\title{
Novel Foraminal Expansion Technique
}

\author{
Ali Fahir Ozer ${ }^{1}$, Salim Senturk ${ }^{1}$, Mert Ciplak ${ }^{2}$, Tunc Oktenoglu ${ }^{2}$, \\ Mehdi Sasani ${ }^{2}$, Emrah Egemen ${ }^{1}$, Onur Yaman ${ }^{1}$, Tuncer Suzer ${ }^{1}$ \\ ${ }^{1}$ Department of Neurosurgery, Koc University School of Medicine, Istanbul, Turkey \\ ${ }^{2}$ Department of Neurosurgery, American Hospital, Istanbul, Turkey
}

The technique we describe was developed for cervical foraminal stenosis for cases in which a keyhole foraminotomy would not be effective. Many cervical stenosis cases are so severe that keyhole foraminotomy is not successful. However, the technique outlined in this study provides adequate enlargement of an entire cervical foraminal diameter. This study reports on a novel foraminal expansion technique. Linear drilling was performed in the middle of the facet joint. A small bone graft was placed between the divided lateral masses after distraction. A lateral mass stabilization was performed with screws and rods following the expansion procedure. A cervical foramen was linearly drilled medially to laterally, then expanded with small bone grafts, and a lateral mass instrumentation was added with surgery. The patient was well after the surgery. The novel foraminal expansion is an effective surgical method for severe foraminal stenosis.

Keywords: Cervical; Foraminotomy; Minimal invasive surgery; Instrumentation

\section{Introduction}

Foraminal stenosis is one of the most important pathologies in patients with radicular signs secondary to cervical spondylosis. A degenerative process causes narrowing of the neural foramina and compression to the nerve root.

In patients with foraminal stenosis, arm pain is more prominent than motor deficits. A variety of treatments can be tried based on the severity of a patient's symptoms. Medical treatments and physiotherapy lose their effectiveness with increasing nerve irritation within the narrowed neural foramina. Transforaminal injections may partially treat pain but pain appears back in time.

Anterior or posterior approaches for surgical decompression and widening of the foramina are effective surgical treatments for these patients. Simple posterior keyhole foraminotomy alone is also ineffective in patients who have severe foraminal stenosis (Fig. 1). We describe this new surgical technique especially for those patients to enlarge the narrowed neural foramina.

\section{Technical Note}

\section{Surgical technique}

The patient was operated in prone position under general anesthesia. The head was fixed with a Mayfield clamp and placed in neutral position. The correct level was identified with C-arm and a midline skin incision was made. The lamina and facet joints were largely exposed following bilateral paravertebral muscle dissection. A self-retaining retractor was inserted and surgical microscope was used

Received Jan 8, 2016; RevisedJan 26, 2016; Accepted Feb 14, 2016

Corresponding author: Ali Fahir Ozer

Department of Neurosurgery, Koc University School of Medicine, Rumelifeneri Yolu Sariyer, Istanbul 34450, Turkey

Tel: +90-212-338-1401, Fax: +90-212-338-1559, E-mail: alifahirozer@gmail.com 


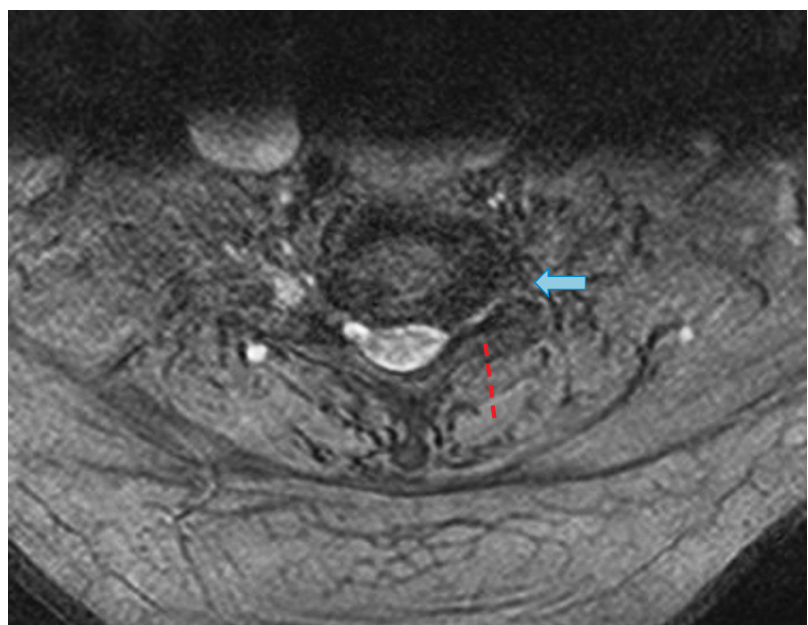

Fig. 1. Magnetic resonance imaging showing narrowing of the foramina (arrow). Classical medial unroofing is not enough for those patients because of severe stenosis.
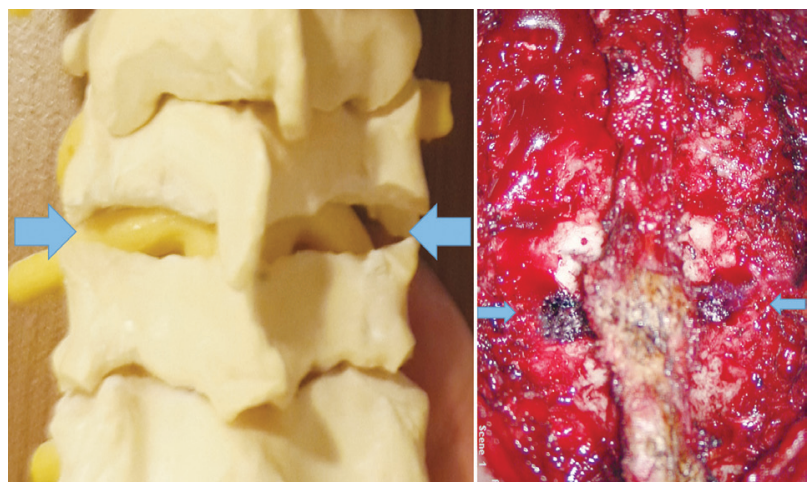

Fig. 2. Facet joints were horizontally opened with high speed drill bilaterally from medial to lateral part (arrows).

from this point of the operation. A small hemi-laminectomy was performed at the inferior part of the lamina and expanded to the facet joint laterally on one side as a classical key-hole foraminotomy. The upper and lower surfaces of facet joint were partially removed with a number 3 high-speed drill from the medial opening to lateral end point horizontally. The remaining thin bone at the anterior part of the facet joint was removed using a 2-mm Kerrison Rongeur. Adequate articular processes were retained for stabilization with lateral mass screws. The foramen was largely exposed and nerve root was totally decompressed. A small amount of bleeding from the venous plexus was easily controlled with surgicell. The enlargement of foramen and decompression of nerve root were completely performed under surgical microscope to prevent any damage and excessed bleeding. The same procedure was also applied to the opposite site (Fig. 2).

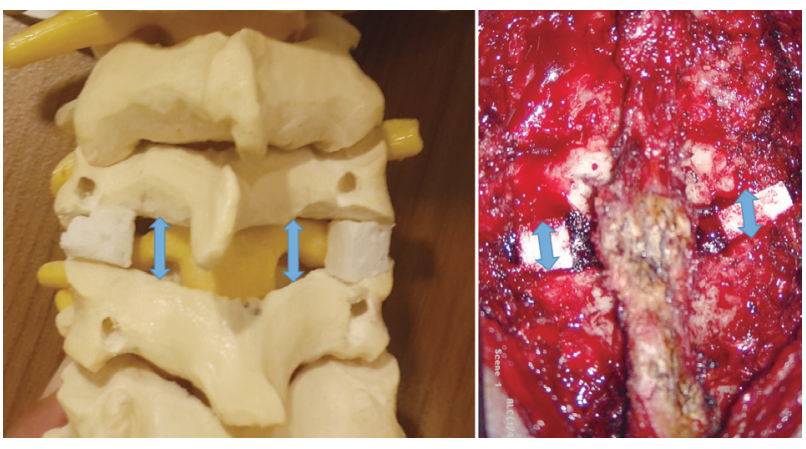

Fig. 3. Small bone grafts are placed between the facet joints after a small distraction (arrows). The foramen is adequately enlarged.

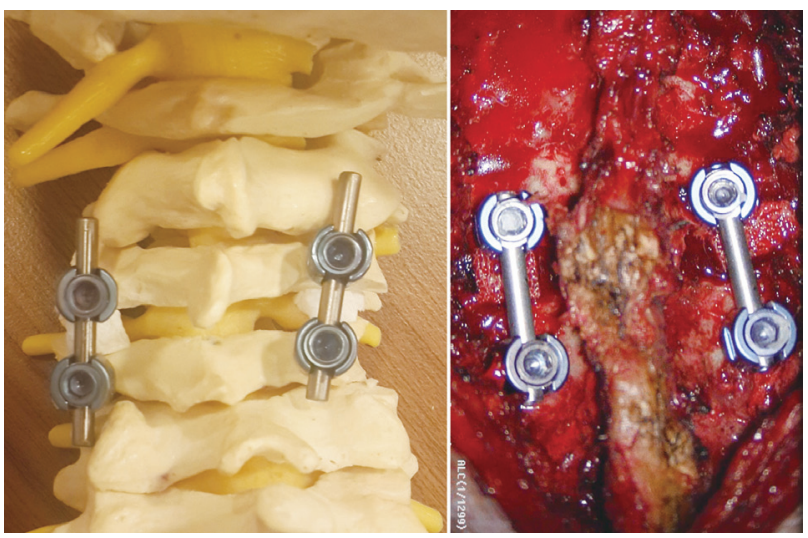

Fig. 4. Lateral masses of the drilled facet joint yield enough bone tissue for a lateral mass screw insertion.

The facet surfaces were distracted to place the bone grafts and provide the ultimate height. An over-distraction was avoided because of the possible risks of nerve root traction and neck pain (Fig. 3). Lateral mass screws were inserted on the upper and lower parts of the facet portions for stabilization and the surgery was completed after placement of rods (Figs. 4, 5).

\section{Discussion}

Based on classic studies, removing one-third of the medial wall of the facet joints relieves the nerve root at the most narrowed part without causing instability [1-5]. Although this procedure is effective in most cases, it is not an adequate treatment in patients with severe foraminal stenosis. To remove the one-third of the medial wall is not enough to create a larger neural foramina and decompress the nerve root. The back wall of a deteriorating vertebrae corpus with the associated osteophytes and hypertrophied facet joint leads to the formation of a long and narrowed 

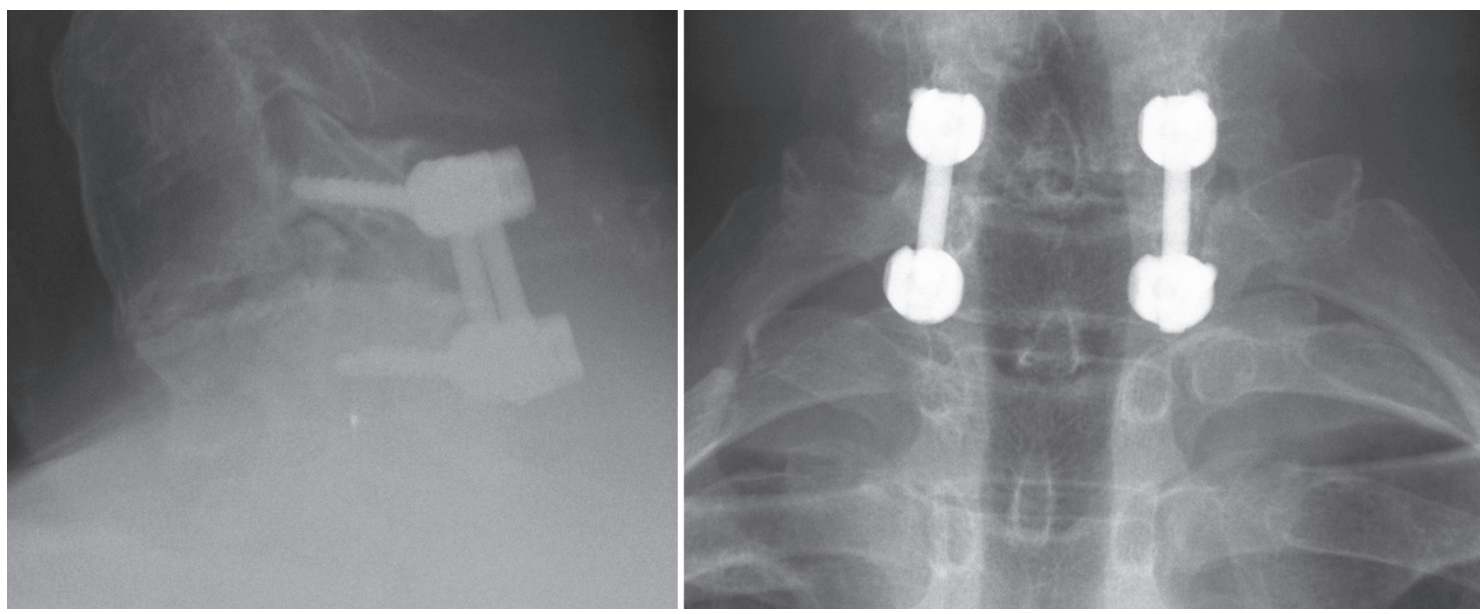

Fig. 5. Lateral and antero-posterior X-ray of the patient after the surgery.

foramen. Thus, it is necessary to remove the entire facet joint to expand this narrow foramen. This total facetectomy procedure leads to instability and serious problems at the severely degenerated segment. Moreover, the operation should include the upper and lower facet joints and fusion has to be added anteriorly to provide sufficient stability. Adding the healthy upper and lower lateral masses into the stabilization system will restrict movements, and anterior surgery will cause unnecessary morbidity.

Placing an amplifier into the vertebral body and distracting the facet joint can expand the foramen and spinal canal $[3,6]$. Subsequently, the DTRAX Facet System (Providence Medical, Lafayette, CA, USA) was developed to distract the facet joint in a minimally invasive manner [7]. However, it may be difficult to apply this technique in a partially degraded facet joint, which has limited movement. In addition, the desired fusion cannot be obtained in those patients. If a metal or inorganic material is used, there may be a collapse under local osteoporotic bones in the long-term, which can cause narrowing of the foramina again.

A tubular approach for foraminal decompression with screw-rod stabilization has been described [8]. The authors unroofed a foramen without distraction. At the same time, they placed screws and rods into the lateral masses. However, in our technique, we distracted to the facet joints and stabilized the spine after the decompression and foraminal enlargement.

A cadaveric human cervical spine anatomic study using posterior lateral mass screw-rod instrumentation assessed foraminal enlargement using distraction techniques [9]. The authors concluded that posterior cervical instru- mented distraction in foraminal stenosis is a reasonable supplement to direct laminoforaminotomy and nerve root decompression. Loading an instrumentation system without fusion causes loosening or instrumentation failure in humans. Although their technique expands the foramen, it is not an acceptable surgery in reality.

The present technique is a simple and safe operation, which can be used in patients who have severe foraminal stenosis without kyphosis. The most important advantage of this technique is the necessity of only one segment stabilization with lateral mass screws. We believe that this procedure is an alternative surgical technique in patients who have radicular signs secondary to nerve root compression in narrowed neural foramina.

\section{Conflict of Interest}

No potential conflict of interest relevant to this article was reported.

\section{References}

1. Gala VC, O’Toole JE, Voyadzis JM, Fessler RG. Posterior minimally invasive approaches for the cervical spine. Orthop Clin North Am 2007;38:339-49.

2. Russell SM, Benjamin V. Posterior surgical approach to the cervical neural foramen for intervertebral disc disease. Neurosurgery 2004;54:662-5.

3. Goel A, Shah A. Facetal distraction as treatment for single- and multilevel cervical spondylotic radiculopathy and myelopathy: a preliminary report. J Neurosurg Spine 2011;14:689-96. 
4. Fessler RG, Khoo LT. Minimally invasive cervical microendoscopic foraminotomy: an initial clinical experience. Neurosurgery 2002;51(5 Suppl):S37-45.

5. Khoo LT, Bresnahan L, Fessler RG. Cervical endoscopic foraminotomy. In: Fessler RG, Sekhar L, editors. Atlas of neurosurgical techniques: spine and peripheral nerves. New York: Thieme; 2006. p.785-92.

6. Goel A. Facet distraction-arthrodesis technique: can it revolutionize spinal stabilization methods? J Craniovertebr Junction Spine 2011;2:1-2.

7. McCormack BM, Bundoc RC, Ver MR, Ignacio JM, Berven SH, Eyster EF. Percutaneous posterior cervi- cal fusion with the DTRAX Facet System for singlelevel radiculopathy: results in 60 patients. J Neurosurg Spine 2013;18:245-54.

8. Mikhael MM, Celestre PC, Wolf CF, Mroz TE, Wang JC. Minimally invasive cervical spine foraminotomy and lateral mass screw placement. Spine (Phila $\mathrm{Pa}$ 1976) 2012;37:E318-22.

9. Jenis LG, Banco S, Jacquemin JJ, Lin KH. The effect of posterior cervical distraction on foraminal dimensions utilizing a screw-rod system. Spine (Phila Pa 1976) 2004;29:763-6. 